Thorax (1949), 4, 65.

\title{
SOME OBSERVATIONS ON THE CO-ORDINATION OF DIAPHRAGMATIC AND . RIB MOVEMENT IN RESPIRATION
}

\author{
BY \\ HERBERT HERXHEIMER \\ Surgical Unit, University College Hospital, London
}

Diaphragm and intercostal muscles together ventilate the lungs. Little is known about the proportion in which they share in this work. Such knowledge, however, is necessary if we want to understand the aetiology of certain respiratory disorders. An attempt has been made, therefore, to investigate the part played by diaphragm and intercostal muscles in the exchange of air.

\section{METHOD}

Tracings of the respiration were made with a spirometer of the Benedict-Roth type to which a flowmeter was attached. Oxygen was supplied continuously through this flowmeter at the same rate at which it disappeared from the spirometer. The tracings were thus kept horizontal. After quiet breathing had been recorded for some minutes the subject was asked, to inhale and exhale fully, and the vital capacity was recorded. This was repeated several times at intervals of one minute or more. At the same time the rib movements were recorded by means of the thoracograph described by Verzár (1945). This instrument permits the accurate tracing of any change in the circumference of the chest at any given level.* It is therefore possible to state how much the chest expands or contracts during a single tidal breath, or during a full inspiration or expiration. The tracing thus appears very similar to a spirometric tracing, showing the level at which the tidal air exchange occurs between the limits of inspiration and expiration (Plate $\mathrm{I} a$ ). But unlike the spirometric tracing it does not represent a volume of air moved but the changes in the circumference of the chest at a certain level. If the tidal air level moves up or down it means that normal quiet breathing is carried out by a more or less inflated chest. As a rule the instrument was applied at the level of the third to fourth ribs.

\footnotetext{
*The apparatus consists of a flat steel band which is put round *The apparatus consists of a flat steel band which is put round
the chest. Its ends are hooked on to a recording machine which the chest. Its ends are hooked on to a recording machine which
rests on the chest. Each expansion of the chest pulls at the recordrests on the chest. Each expansion of the chest pulls at the record-
ing pencil, which records its movements on rotating wax paper. Contraction of the chest permits a spring to pull the pencil back towards its previous position. The advantage of this apparatus compared with the stethograph is that its recordings are in direct proportion to the actual changes in chest circumference.
}

The simultaneous use of both tracings serves the purpose of studying separately the extent of the diaphragmatic and rib movements. The volume of the total air exchange, as given by the spirometer tracing, depends on both diaphragmatic and costal movement. If, at the same time, costal movement is recorded separately, the comparison of the tracings will permit a conclusion as to the contribution of the costal movement to the volume of air exchange. If their excursions remain in the same proportion the shares taken by diaphragm and ribs have remained constant. If the diaphragm takes no part in the ventilation, the rib movement can be expected to increase to its maximum. This form of pure costal breathing is sometimes seen during the asthmatic attack. If the diaphragm only is active, no rib movement will be seen on the tracing. This can be noticed frequently in normal subjects during quiet breathing. In many cases, and in almost all in whom breathing exceeds the basal requirements, the share of ribs and diaphragm changes rapidly and continuously, as may be expected of a function controlled by so many factors.

The range of rib movement to be expected can be seen from the following mathematical consideration: If the thorax is regarded as a cylinder with a radius of $\frac{50}{\pi}$ and a height of $20 \mathrm{~cm}$., its circumference would be $c=100 \mathrm{~cm}$. For an increase of $\mathrm{c}$ from $100 \mathrm{~cm}$. to $102 \mathrm{~cm}$. the volume of the cylinder would increase by $636 \mathrm{c.cm}$. Therefore, for $100 \mathrm{c.cm}$. change of volume the change of the circumference would be $\frac{20}{6.36}=3.2 \mathrm{~mm}$. This calculation is, of course, only approximately valid for the thorax, as its shape is irregular. Were it to hold for pure costal movement, we should, in practice, not observe higher values than $3.2 \mathrm{~mm}$. per $100 \mathrm{c.cm}$. ventilation. In fact, such high values are rare in normal subjects. Only in four experiments out of 70 , values between 3.0 and 3.6 were observed, the latter occurring only once. A number of asthmatic patients, however, showed values of just under $4.0 \mathrm{~mm}$. during an attack, at a time when the diaphragm was in a low position, and when no movement could be seen radiologically which could be clearly identified as inspiratory or expiratory. 
It is therefore assumed that almost pure rib movement is present if the movement of $100 \mathrm{c.cm}$. of air requires 3.5 to $4.0 \mathrm{~mm}$. change in chest circumference, and that pure diaphragmatic movement is present when no rib movement can be recorded. As these extremes are the exception, and the simultaneous action of diaphragm and ribs the rule, at least in normal subjects, it is impossible to assess their. absolute shares by our method of simultaneous recording. It is, however, possible to observe changes in the proportion of their share under various conditions-for instance, in the production of the complemental and the reserve air, in the inspiratory and expiratory movement, and in changes of body position.

The use of this method is limited by the fact that it does not give absolute values. Another limiting factor is that the movement of the upper ribs does not necessarily represent a'so the movement of the lower ribs. For this reason we have in some cases measured the chest circumference also at the level of the eighth to ninth ribs. A further possible source of error is that the ribs move more air per $\mathrm{mm}$. chest expansion as the chest becomes wider. If one regards the chest circumference as the circumference of a cylinder with the radius $r$, the volume of this cylinder will be $\pi r^{2} h$. An increase of $r$ by, say, $1 \mathrm{~mm}$. will cause the cylinder volume to increase more when $r$ is large than when $r$ is small. If this is applied to the chest it means that the increase of circumference by $1 \mathrm{~mm}$. of an inflated chest will produce a greater increase of volume than the same circumference increase of a deflated chest. However, the difference can be shown to be small. If the chest circumference in full expiration be $100 \mathrm{~cm}$. and increases by $1 \mathrm{~mm}$., its volume will increase by $31.8 \mathrm{c.cm}$. if its height is $20 \mathrm{~cm}$. If the same happens in full inspiration at $110 \mathrm{~cm}$. circumference, the volume increase will be $38.2 \mathrm{c.cm}$. The difference of $6.4 \mathrm{c} . \mathrm{cm}$. between these two extremes will not be of importance for our observations.

A convenient way of determining the relative activity of ribs and diaphragm during ventilation is to express the costal movement in $\mathrm{mm}$. per $100 \mathrm{c} . \mathrm{cm}$. of air exchanged. As has been shown, the maximum of this figure will lie near $4 \mathrm{~mm}$.; it represents almost pure costal movement, whilst its minimum, during pure diaphragmatic movement, will be zero. The higher the figure, the more rib movement is involved. A figure below $0.5 \mathrm{~mm}$. will mean that very little costal movement and mainly diaphragmatic movement has taken p'ace, whereas a figure above $3.0 \mathrm{~mm}$. indicates little diaphragmatic activity with prevalent costal movement. This method has been used for the investigation of the subdivisions of the vital capacity in various positions of the body. The modifications used for other conditions will be described under the appropriate headings.

\section{COMPlemental and Reserve Air}

Fourteen (eight female, six male) healthy subjects between 15 and 25 years of age were trained till their breathing was fairly regular and they could be relied upon to produce the same vital capacity within a range of $150 \mathrm{c.cm}$. at any time.

Standing Position.-The results are shown in the Table, and a representative example is given in Plate Ia. The two graphs have been adapted photographically so that both are read from left to right and cover the same distance for the same time interval. It can be seen that both tracings are similar: the tidal air is easily identified in both, and the measurement of the maximum inspiration from the upper limit of the tidal air (we have excluded the tidal air from the complemental air) and of the maximum expiration from the lower end of the tidal air (reserve air) is a very simple procedure.

The Table shows, in spite of great individual variation, some remarkable uniformity for the standing position: the complemental air (the upper figure) lies, with one exception, above 2 and several times above $3 \mathrm{~mm}$.; whilst the lower figure, representing the reserve air, in all cases but one is below 1.0 and often below $0.5 \mathrm{~mm}$. This means that in almost all cases the ventilation has been carried out by both ribs and diaphragm, but that the ribs had very little or practically no share in the movement of the reserve air. The share of the ribs in the movement of the complemental air, however, is considerable.

The observation that the reserve air is moved mainly by the diaphragm increases the diagnostic importance of the reserve air. We know that in emphysema the diaphragm is kept at a low level, and that it cannot be lowered very much more on maximum inspiration. We would therefore expect the complemental air in emphysema to be small, as it would be moved mainly by the ribs, with little support from the diaphragm. On the other hand, the reserve air should be enlarged because from its lower level the diaphragm (if it is fully mobile) can be moved upwards over a greater distance than from a medium level in a normal person. Both expectations are confirmed by actual observation. In emphysema the reserve air is often increased and the complemental air correspondingly small. There are a number of people in whom this is not so. In these the diaphragm is not fully mobile, either because of the opposing bronchial spasm or for other reasons. Under such conditions the vital capacity is considerably reduced, and in those patients with moderate emphysema in whom it is normal or little reduced the reserve air percentage is, in my experience, always abnormally large. Other observers have had similar results. Hurtado and others (1934) 
TABLE

CHANOB OF CHEST CRCUMAFRENCE IN MM. FOR 100 C.CM. OF AIR EXCHANGED

(Upper figure: complemental air; lower figure: reserve air).

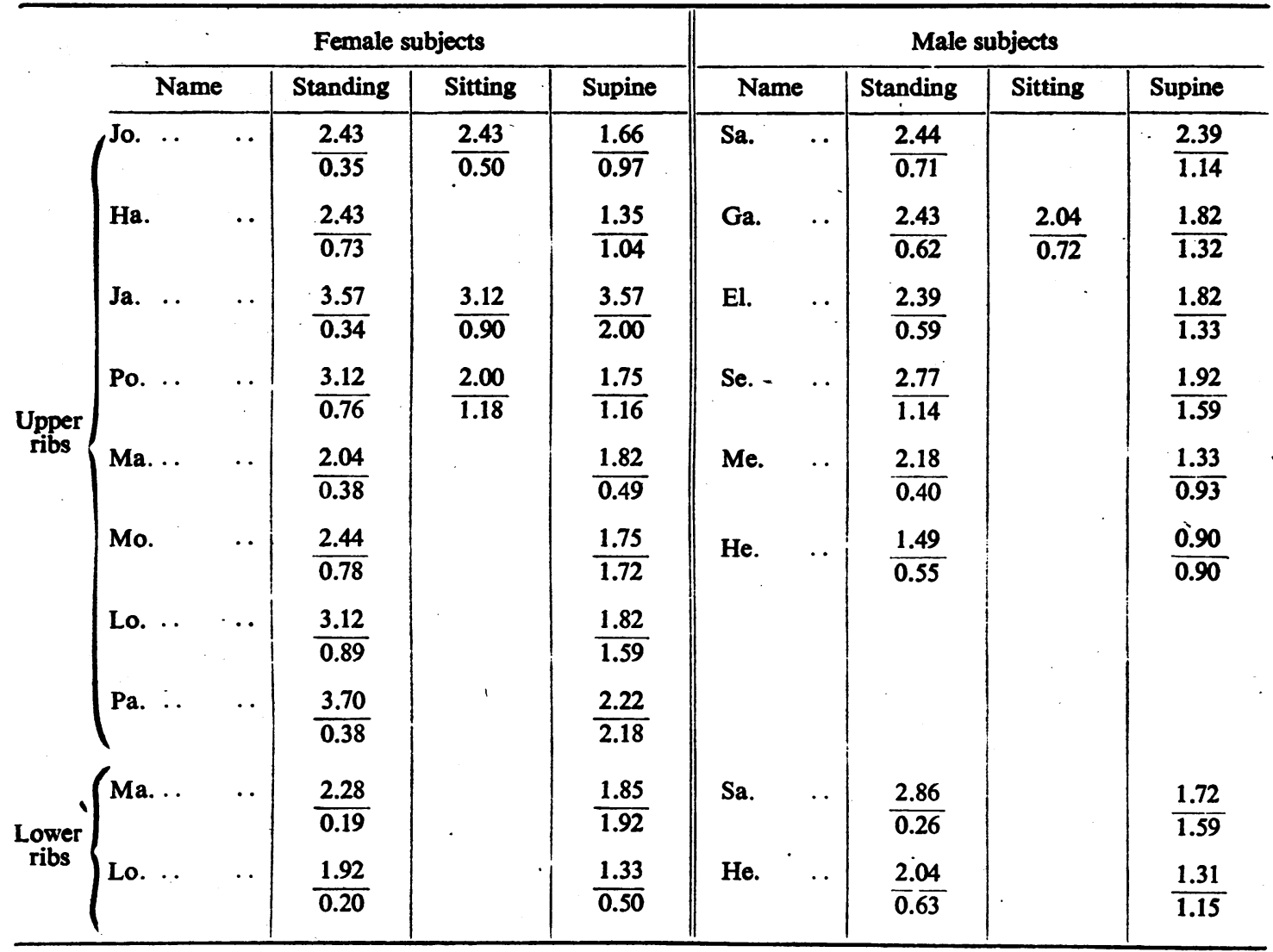

have seen an average reserve air of 29.2 per cent of the vital capacity in 26 cases of emphysema, whilst their normal cases in the same position (supine) show an average between 17 and 23 per cent of the vital capacity (Hurtado and others, 1934 ; Kaltreider and others, 1938). Jimenez Diaz and others (1942) also found the reserve air increased.

Another practical application of our observations concerns subjects in whom the reserve air is small. This occurs in obese persons who have a large amount of fat in the abdomen and in whom the diaphragm is found at an abnormally high level.* In these persons a small reserve air can be expected, as the diaphragm cannot rise as much from a high level position as it could from a normal mid-position. Observation shows that most obese persons have indeed an abnormally small reserve air.
Another such correlation of diaphragmatic action and reserve air is found in the transition from the standing to the supine position. As Hofbauer (1921), Livingstone (1928), and Herxheimer (1948) have shown, the level of the diaphragm shifts upwards when the position of the patient changes-from standing or sitting to lying. Kaltreider and others (1938) have shown that at the same time the reserve air decreases sharply (from 30 per cent in the sitting position to 18 per cent in the lying position). I have found a similar difference in the transition from standing to lying (from 37 per cent to 24 per cent).

The tidal air in the standing position is often exchanged without any noticeable participation of rib movement. There are, however, great individual variations. In many subjects rib movement is absent, or almost absent, when they are standing 
in a relaxed attitude - for instance, leaning against a wall. Breathing is, under these circumstances, exclusively diaphragmatic. But the slightest muscular exertion or, in some persons, excitement brings the ribs into action at once, and this will continue for some minutes after cessation of the cause.

The lower part of the Table shows the values found when the thoracograph was applied to the lower instead of the upper ribs. The absolute figures, as one would expect, are different from those for the upper ribs, but the essential difference between the complemental air and the reserve air remains the same: the share of the diaphragm in the movement of the reserve air is very much greater than in the movement of the complementary air ; in three out of the four subjects the ribs have hardly any share.

Supine and SitTing Positions.-There is a definite difference between the results in the supine and in the standing positions, as shown in the Table. The complemental air (upper figures) still shows higher values than the reserve air (lower figures). This indicates that in the complemental air movement the diaphragm has a smaller share than in the reserve air; but the difference between them is not as pronounced as in the standing position, and in a few subjects the shares are even identical for both subdivisions. On the whole, the share of the ribs in the complemental air is not as marked as before, although prevalent, and the share of the diaphragm in the reserve air is not as predominant and almost exclusive as in standing.

In order to understand this, we must remember that, during transition to the lying position, the diaphragm is shifted upwards. This results in a decrease of vital capacity, and especially of the reserve air. At the same time the chest, in most persons, becomes a little wider, to compensate partly for the loss of volume caused by the ascending diaphragm. The ribs have to work now in a more outward position than before and seem more restricted in their extreme inspiratory movement. The diaphragm, on the other hand, is restricted in its extreme expiratory movement by its original high level. It can now, from its higher level, breathe in deeply "more easily" than it can breathe out. Hence its smaller share in reserve air and bigger share in complemental air.

The change is reflected also in the tracings of the tidal air. Whilst in many persons during standing the tidal air is exchanged without rib participation, the ribs become active in the lying position. This can be seen, for instance, in Plate $I a$, which is representative for the majority of subjects examined. There is very little costal movement in the standing, and a pronounced increase in the lying, position.

A few investigations have also been made in the sitting position, and the values obtained are included in the Table. As might have been expected, most of the figures lie between those obtained in the standing and the lying positions.

\section{INSPIRATION AND EXPIRATION}

Originally it was taken for granted that inspiratory and expiratory movements were strictly reciprocal : if, for instance, a complemental air of $1,500 \mathrm{c.cm}$. was inspired by costal and diaphragmatic movement in a certain proportion, it was assumed that the reverse expiratory movement would be carried out in the same proportion. Some observations, however, threw doubt on this assumption. It was seen, for instance, that after a maximum inspiration the chest circumference did not return to its former value but remained greater than before, although exactly the same amount of air had been exhaled as had been inhaled. This indicated that the diaphragm must have assumed a higher level than before. An example of this can be seen in Plate IIb (point E).

This and similar observations made it desirable to investigate whether single fractions of the complemental and of the reserve air were moved by constant proportions of diaphragmatic and costal actions. For this purpose the subject was placed so that he could watch the recording drum of the spirometer. After some quiet breathing he was asked to begin a maximum inspiration but to hold his breath for about five seconds at a certain point, indicated to him on the spirometer tracing, usually midway between tidal air and inspiratory limit or nearer to the latter. Then he continued the inspiration to its limit and exhaled immediately, but stopped during expiration at exactly the same point where he had interrupted his inspiration. After a further five seconds he continued the expiration and breathed quietly for some while. Then the procedure was repeated with a different point of interruption. Maximum expirationreserve air-was treated likewise. The holding of the breath was just long enough to cause an interruption in both spirometric and chest tracings at corresponding points. If the tracings are synchronized, as in Plate II, it is a simple matter to compare different portions of the complemental and reserve air and the part that ribs and diaphragm have played in their movement.

It is surprising to see that inspiration and expiration are not carried out in the same manner. In the experiment reproduced in Plate II $a$, for 


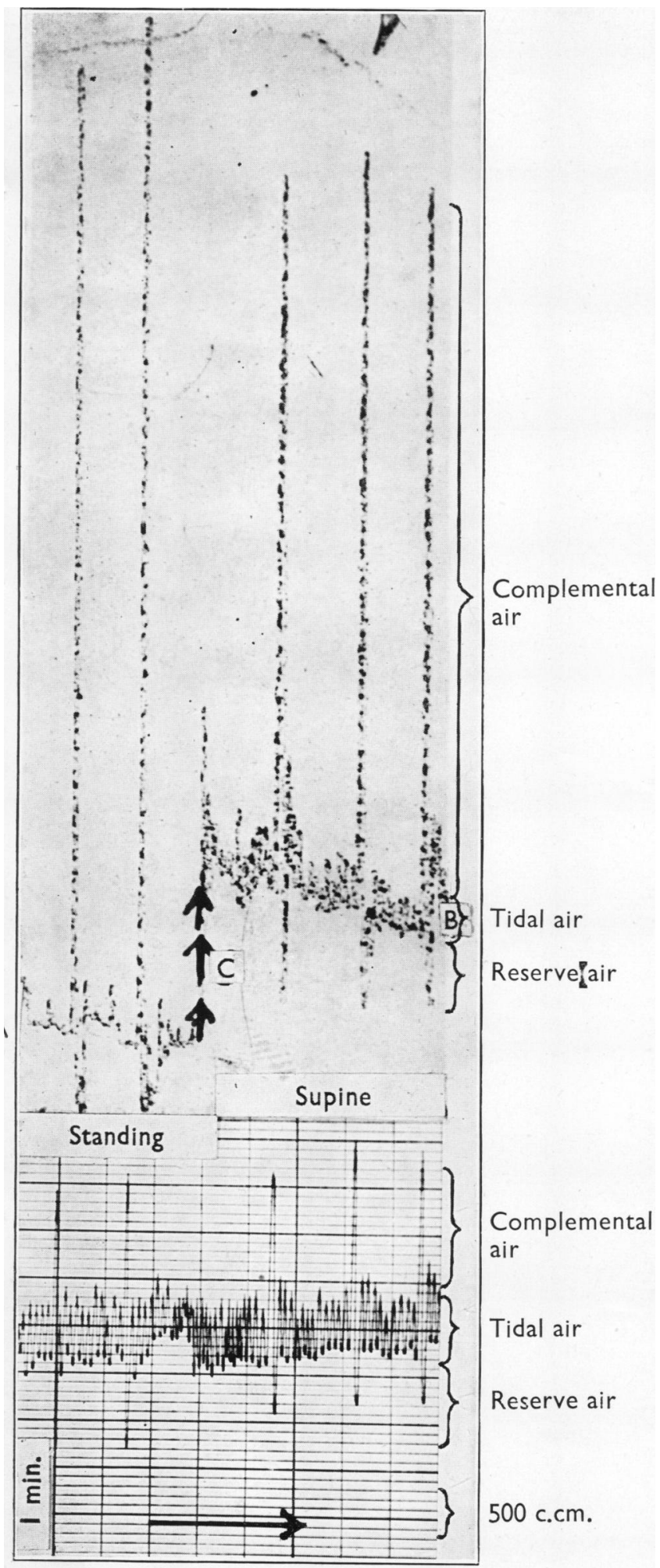

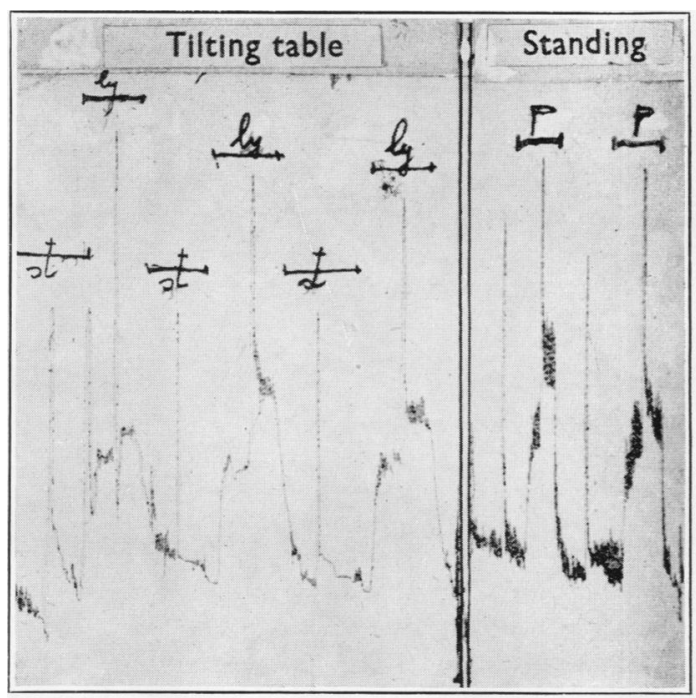

(b)

Plate I.-(a) Upper part: thoracometer tracing; lower part: spirometer tracing. Note: (1) Costal movement during quiet breathing is almost absent in the standing (at A), but present in the supine position (at B). (2) The tidal air level of the chest circumference has risen on transition from the standing to the supine position (at C); the chest is now wider than before. (b) Left portion: thoracogram of a subject changing from the standing position to the supine position on the tilting table. In each position one maximum inspiration is taken. (st $=$ standing, ly = supine.) It can be seen that in the supine position the chest circumference is greater than in the standing position, both in quiet breathing and in maximum inspiration. Right portion: thoracogram of the same subject in the standing position. During the periods marked $\mathbf{P}$ pressure has been exerted on the abdominal wall. One maximum inspiration is carried out without pressure and one under pressure. It can be seen that under pressure the chest circumference is greater than without, both in quiet breathing and in maximum inspiration. 


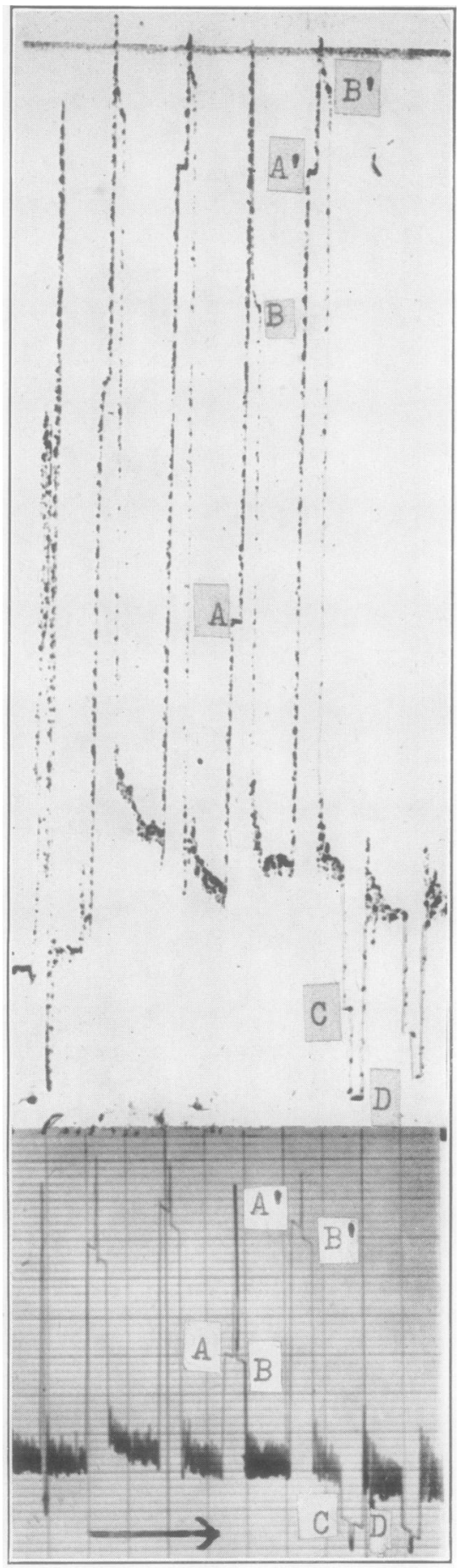

(a)

PLATE II.-(a) Upper part: thoracometer tracing; lower part: spirometer tracing. At points $A$ and $B$ the breath was held at about $2,200 \mathrm{c} . \mathrm{cm}$. below the inspiratory limit, and at points $A^{\prime}$ and $B^{\prime}$ at about $750 \mathrm{c} . \mathrm{cm}$. below it. At points $C$ and $D$ the breath was held about $400 \mathrm{c.cm}$. above the expiratory limit. (b) Upper part: thoracometer tracing; lower part: spirometer tracing. Showing at $\mathrm{E}$ failure to return to former level on expiration, so that the diaphragm must be assumed at a higher level than before. At A and $B$ the breath was held $700 \mathrm{c} . \mathrm{cm}$. and at $A^{\prime}$ and $B^{\prime}$ $1,300 \mathrm{c.cm}$. below the inspiratory limit.

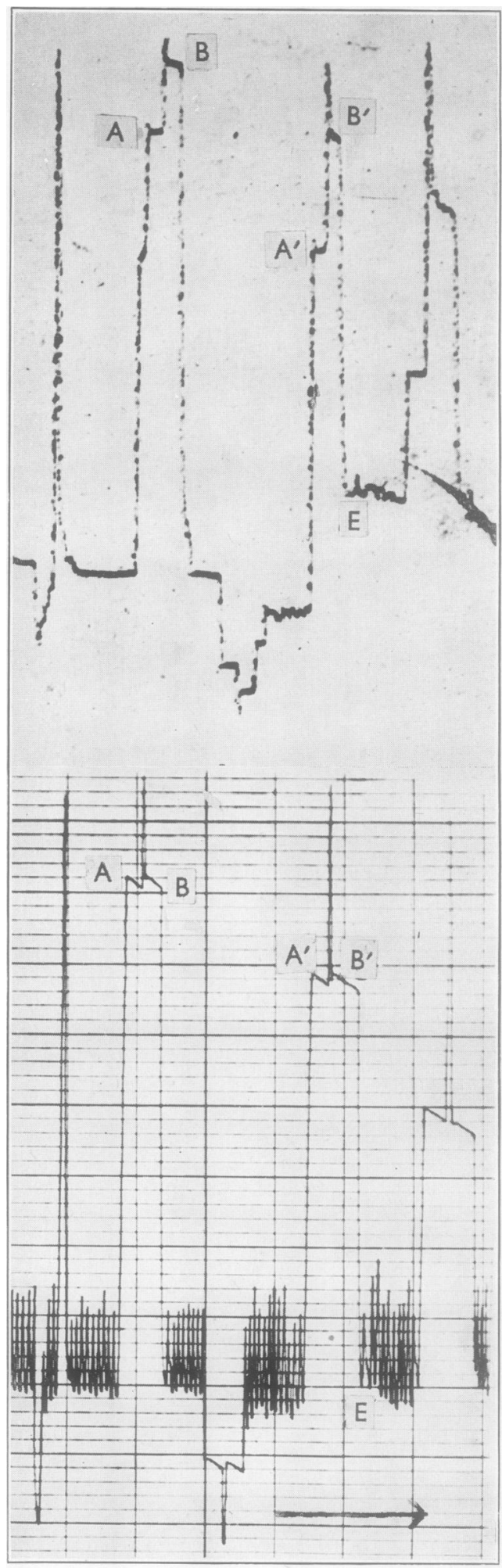

(b) 
instance, the subject held his breath at the same chest volume during inspiration as during expiration. At points $A$ and $B$ it is held at about 2,200 c.cm. below the inspiratory limit, and at points $A^{\prime}$ and $B^{\prime}$ it is held at about 750 c.cm. below it, as seen on the spirometric tracing. If the chest tracing is compared with it, these points lie far apart. In both cases the inspiration has been carried out with a similar share of ribs and diaphragm before and after the interruption, the rates for the costal movement varying not more than from 1.30 to $1.68 \mathrm{~mm}$. for $100 \mathrm{c.cm}$. of air. Expiration is quite different. The top parts (above $B$ and $B^{\prime}$ ) are done mainly by the diaphragm, and only in the lower parts do the ribs begin to act. The figures for the chest movement during expiration are 0.83 and $0.40 \mathrm{~mm}$. for $100 \mathrm{c.cm}$. of air for the top part, and 4.0 and $1.96 \mathrm{~mm}$. for the lower part. $4.0 \mathrm{~mm}$. indicates an almost pure costal movement. This experiment, therefore, shows the following: inspiration is carried out by the combined action of both ribs and diaphragm during the whole movement, although they do not act in constant proportion all the time. The expiration starts with a lifting of the diaphragm whilst the ribs are held at their inspiratory limit; later, the diaphragm moves much less, and in the first example (AB) is kept still, whilst the ribs come out of their inspiratory position and complete the expiration alone. The example in Plate II $b$ shows a very similar picture. For the $700 \mathrm{c.cm}$. of air on top of points $A$ and $B$ the ribs have moved $0.63 \mathrm{~mm}$. per 100 c.cm. in inspiration and $0.14 \mathrm{~mm}$.- hardly at allin expiration. The figures for points $\mathbf{A}^{\prime}$ and $\mathbf{B}^{\prime}$ are 0.77 and $0.27 \mathrm{~mm}$. for inspiration and expiration.

Similar experiments with the reserve air give corresponding results. The first movement, in this case expiratory, has been interrupted about midway (at $\mathrm{C}$ ), and the shares of ribs and diaphragm are about the same before and after the break (near $2.0 \mathrm{~mm}$.). The inspiration, however, starts with a purely diaphragmatic action, and no rib movement is recorded for these $350 \mathrm{c} . \mathrm{cm}$. The part after the interruption is carried out by both, but predominantly by the ribs $(3.1 \mathrm{~mm}$.).

Five different subjects were investigated in the same way, and although there are considerable variations similar proportions as shown in Plate II were found. In most cases the second respiratory movement (expiratory for the complemental, inspiratory for reserve air) was carried out with little or no movement of the ribs at first, near the inspiratory and expiratory limits, the diaphragm doing most of the work. Later, when nearing the mid-position, the ribs take a greater or even predominant part of the work. There are exceptions to this rule. Another frequent but less regular occurrence is the tendency of the diaphragmatic action to predominate in both respiratory phases near the inspiratory and expiratory limits, though more in the second.

Staehelin and Schütze (1912) have found by recording costal and abdominal movement stethographically that during quiet breathing the diaphragm is slightly more active in the end-positions. Our observations lie in the same direction. They show that diaphragm and costal muscles do not work together in a constant proportion. The proportion varies widely in different subjects, and it changes rapidly in the same subject during different stages. There is a continuous interchange between rib muscles and diaphragm, the co-ordination of which must require a very intricate nervous mechanism. An astonishing feature is that the volume of air in the chest at mid-position remains the same, as seen from the constant tidal air level on the spirometer tracing. If the ribs assume another "tidal air level" (Plate II $b$, point E) the diaphragm compensates for it by assuming a higher or lower level. In some subjects this compensating mechanism does not function as well as in others.

Our observations are supported to a certain extent by screening. If a subject carries out deep inspirations and expirations slowly, it can be seen that at times the diaphragm hardly moves, although the respiration is continuing at an even rate. This phenomenon was first reported by Hofbauer (1921). It indicates that ribs and diaphragm predominate alternately in ventilation.

\section{The Effect of Abdominal Pressure}

It is known that pressure on the abdominal wall displaces the diaphragm upwards (Herxheimer, 1948). It was found that at the same time, in spite of this obstacle to the diaphragmatic movement, the vital capacity decreased only very little. We have recorded the effect of abdominal pressure on the circumference of the chest. Plate $I b$ (right part) shows a thoracometer tracing made while the subject was standing, leaning comfortably against a wall. In this position a maximum inspiration and corresponding expiration to tidal air level was taken. Then manual pressure was applied to the abdomen (this part of the tracing is marked $P$ ). It can be seen that the tidal air level moves upwards at once. This increase of the chest circumference is 14 to $18 \mathrm{~mm}$. If now another maximum inspiration is taken, the chest becomes wider than it was at the height of inspiration without abdominal pressure. 
The widening of the chest compensates for the loss of chest volume caused by the higher level of the diaphragm. It happens during quiet breathing in most subjects and may reach $20 \mathrm{~mm}$. The increased expansion during maximum inspiration is not observed so regularly. It seems to depend on the individual ability of lifting the ribs into a higher and more outward position. The same increase in chest circumference can be obtained if the subject holds his breath in maximum inspiration and pressure is applied to the abdomen: the chest becomes wider under this pressure and resumes its former shape when the pressure is released.

In many cases the external pressure on the abdomen can be replaced by the weight of the abdominal viscera pressing against the diaphragm in the supine position. The left part of Plate $\mathrm{I} b$ shows an experiment with the same subject on the tilting table. When the subject is tilted into the supine position, the chest circumference during quiet breathing increases. If now a maximum inspiration is taken, the circumference becomes greater than it was when this was done in the standing position. It can also be seen that the costal movement during quiet breathing is greater when the diaphragm is at a higher level and the chest is therefore wider. This recalls a common observation: after a heavy meal many people appear to breathe heavily, and this is relieved by loosening the belt. In this case the external pressure of the belt has forced up the diaphragm and caused the chest to widen. At the same time it induces stronger costal movements and a feeling of breathlessness, which is quickly relieved when the belt is loosened and the former type of respiration-diaphragmatic breathing-is resumed.

\section{Conclusions and Summary}

1. The changes of the chest circumference have been recorded simultaneously with the air volume exchanged. This permits an estimation of the share that the diaphragm and the costal muscles have in various phases of respiration.

2. In the standing position quiet breathing is often purely diaphragmatic, whilst in the supine position the costal muscles take a greater part in it.

3. The complemental air is moved by both diaphragm and costal muscles, but predominantly by the latter. The reserve air is moved predominantly by the diaphragm, and in the standing position $\frac{C_{0}}{0}$ often almost exclusively. In the supine position $\overline{\frac{}{\omega}}$ the differences mentioned are less pronounced and $\overrightarrow{\mathbb{D}}$ there is a tendency towards an even share.

4. The direct relationship of diaphragmatic ${ }^{\text {कs }}$ movement and reserve air increases the diagnostic $\vec{\circ}$ importance of the latter. An increased reserve air $\vec{\omega}$ indicates a low level diaphragm of good mobility. A decreased reserve air indicates either a reduced $\vec{x}$ mobility or a high level of the diaphragm. A consistently increased reserve air is of diagnostic significance in emphysema.

5. The proportion of costal and diaphragmatic음 movement changes throughout the respiratorycycle. After the inspiratory or expiratory limit has been reached by the concerted action of both, the diaphragm starts the reverse movement, while the ${ }^{\Im}$ ribs are kept in position or move only little; laterc $\overrightarrow{0}$ they join in, and near mid-position take over mostẹ of the action.

6. Lifting of the diaphragm, either by pressure on the abdomen in the standing position or by the pressure of the abdominal viscera in the supine position, causes an increase of the chest circumfer $-\frac{\mathbb{Q}}{2}$ ence during quiet breathing. On maximum inspira $-\overrightarrow{\overrightarrow{0}}$ tion the ribs can be lifted more under such pressure 3 than without it. This accounts for the small reduc-? tion in vital capacity in spite of the considerablyo higher level of the diaphragm.

\section{REFERENCES}

Diaz, C. J., Agesa, A., and Alemany, M. (1942). Clin. Espan., 5, 241; 5, 413.

Herxheimer, H. (1948). Thorax, 3, 122.

Hof bauer, L. (1921). "Atmungspathologie und Therao pie." Berlin and Vienna.

Hurtado, A., Fray, W. W., Kaltreider, N. L., and Brooks $\frac{D}{0}$ W. D. (1934). J. clin. Invest., 13, 169.

Hurtado, A., Kaltreider, N. L., Fray, W. W., Brooks N W. D., and McCann, W. S. (1934). J. clin. Invest.; 13, 1027.

Kaltreider, N. L., Fray, W. W., and Hyde, H. V. ZN్ (1938). Amer. Rev. Tuberc., 37, 662.

Livingstone, J. L. (1928). Lancet, 1, 754.

Verzár, F. (1945). "Höhenklimaforschungen des Basle Physiologischen Instituts." p. 77. Basle: Bennợ Schwabe.

Staehelin, R., and Schütze, A. (1912). Z. klin. Med.ர $75,15$. 